\title{
F Problemática constitucional del pin parental frente a la educación sexual y de género'
}

\author{
Constitutional conflict of pin \\ parental against sexual and \\ gender education
}

\author{
SERGIO SIVERIO LUIS \\ Profesor Ayudante de Derecho Constitucional. \\ Universidad de La Laguna. \\ ssiverio@ull.edu.es
}

DOI: https://doi.org/10.7203/cc.2.21452

Fecha de recepción: 19/08/2021

Fecha de aceptación: 06/10/2021

\section{Resumen}

El establecimiento de la autorización familiar expresa para participar en actividades complementarias por parte del gobierno autonómico de la Región de Murcia ha generado una polémica controversia que cuestiona la conformidad de la medida con el ordenamiento jurídico y con el marco constitucional. El denominado pin parental pone el foco en las actividades complementarias de educación sexual y de género que se imparten en las escuelas públicas, por cuanto podrían vulnerar el derecho de las familias a educar de acuerdo con sus propias convicciones, debiendo ser voluntarias para el alumnado. En este trabajo, abordaremos la problemática constitucional del pin parental con respecto a la educación sexual y de género, para fundamentar jurídicamente si es compatible o no con la Constitución.

\section{Palabras clave}

Pin parental; educación sexual; familias; infancia; adolescencia; menores; educación; ideario educativo constitucional.

\begin{abstract}
The establishment of mandatory family authorization to participate in complementary activities by the Region de Murcia has generated a legal controversy, which questions its compliance with the legal system and the current constitutional framework. The so-called parental pin focuses on the complementary sexual and gender education activities that are taught in schools, since they could violate the right of families to educate children and adolescents in accordance with their own convictions and should be volunteers for the students. In this investigation, we will address the constitutional problem of the parental pin with respect to sexual and gender education, to legally substantiate its compatibility or not with the Constitution.
\end{abstract}

\section{Keywords}

Parental pin; sexual education; education; family; childhood; adolescence; underage; education; constitutional educational ideology.

1 Este trabajo es parte del proyecto de I+D+i “Vulnerabilidad, precariedad y brechas sociales. ¿Hacia una redefinición de los derechos fundamentales?" (PID2020-114718RB-IOO), financiado por el Ministerio de Ciencia e Innovación y la Agencia Estatal de Investigación (10.13039/501100011033). 
I. Introducción. - II. Controversia del pin parental y régimen jurídico de las actividades complementarias. 1. Antecedentes del pin parental en la Región de Murcia y estado de la cuestión. 2. El régimen jurídico de las actividades complementarias en el sistema educativo. - III. El encaje jurídico constitucional de la educación sexual y de género. 1. El derecho fundamental a la educación y sus fines constitucionales. 2. El reconocimiento del derecho a la educación sexual y de género en el plano internacional y la legislación estatal. 3. La educación sexual y de género como parte del ideario educativo constitucional: límites y garantías para las familias. - IV. Conflictos relativos a la titularidad y ejercicio de los derechos educativos. 1. Las personas menores como titulares del derecho fundamental. 2. La posición singular de las familias para decidir la formación religiosa y moral de la infancia. - V. Conclusiones. Bibliografía.

\section{Introducción ${ }^{2}$}

El derecho fundamental a la educación proclamado en el artículo 27 de la Constitución Española ha sido objeto de numerosas discusiones políticas y doctrinales en nuestra reciente historia constitucional, fruto de la tradicional tensión entre el denominado «ideario educativo constitucional» ${ }^{3}$ (art. 27.2 CE) y la libertad de enseñanza moral y religiosa de las familias ${ }^{4}$ (art. 27.3 CE). Un conflicto que también estuvo presente en el proceso constituyente y que alumbró un precepto constitucional peculiar y especialmente largo (Cotino Hueso, 2012: 6).

La más reciente de estas discusiones ha girado en torno al denominado «pin parental $»^{5}$, una medida que supone la obligatoriedad de autorización familiar expresa para que el alumnado pueda asistir a actividades complementarias de diversas temáticas, entre ellas sobre educación sexual. En este trabajo abordaremos la problemática de la implementación del pin parental en la Región

2 Este artículo es una adaptación del trabajo de fin del Máster en Derecho Constitucional de la Universitat de València, fue dirigido por el Profesor Dr. Cotino Hueso y se han incorporado las valiosas sugerencias del profesorado que integró el tribunal, a quienes quiero agradecer sus aportaciones y consejos.

3 Expresión acuñada por TOMÁS Y VALIENTE en el voto particular a la STC 5/1981, de 13 de febrero.

4 Se ha decidido usar lenguaje jurídico inclusivo, por la importancia de incluir a las mujeres y otros colectivos oprimidos, lo que es defendido cada vez más por la doctrina y avalado por la Red Feminista de Derecho Constitucional. Cfr. Sevilla Merino (2018: 81) y Marrades et al. (2019: 127).

5 Denominado así metafóricamente, en alusión a la contraseña que las familias pueden crear en dispositivos digitales para evitar que las personas menores accedan a algunos contenidos (Rey Martínez, 2021: 22). 
de Murcia, que puede replicarse en otras Comunidades y analizaremos si es conforme a la Constitución.

Así, trataremos de aportar una fundamentación jurídica que nos permitirá evaluar la admisibilidad de una medida que apela a consensos constitucionales (Teruel Lozano, 2020) y es objeto de controversias políticas, por lo que se requiere para su resolución de argumentos científicos rigurosos que trasciendan la guerra partidista. Y ello para abordar un conflicto abierto en el que las personas menores vuelven a ser las grandes damnificadas como titulares del derecho a la educación, a las que rara vez se escucha como protagonistas de la formación que reciben y que, a mi juicio, requieren que les prestemos toda nuestra atención para zanjar la polémica -artificiosa o real- del pin parental.

\section{Controversia del pin parental y régimen jurídico de las actividades comple- mentarias}

\section{Antecedentes del pin parental en la Región de Murcia y estado de la cuestión}

El pin parental es una iniciativa del partido político VOX, incluida en su programa para las Elecciones Autonómicas de 2019 y una de sus condiciones para apoyar la investidura de gobiernos autonómicos en la Región de Murcia, Andalucía o la Comunidad de Madrid. A lo largo de la legislatura, además, se presentaron mociones en los parlamentos autonómicos en las que puede extraerse que el pin parental consiste en informar a las familias "a través de una autorización expresa, sobre cualquier materia, charla, taller o actividad que afecte a cuestiones morales socialmente controvertidas o sobre la sexualidad, que puedan resultar intrusivas para la conciencia y la intimidad de sus hijos, de tal modo que como padre o madre pueda conocerlas y analizarlas de antemano, reflexionar sobre ellas y, en base a ello, dar consentimiento - o no- para que su hijo asista a dicha formación» (Climent Gallart, 2020: 105) .

En la Región de Murcia la polémica medida, integrada al acuerdo de gobierno suscrito por el PP y Ciudadanos, se implementó con las Resoluciones de la Consejería de Educación, de 29 de agosto de 2019, que establecían las instrucciones de inicio del curso 2019-2020 en los distintos niveles (Teruel Lozano, 2021). Así, se establecía que en las actividades complementarias impartidas por personal externo al centro «se dará conocimiento a las familias [...] con objeto de que puedan manifestar su conformidad o disconformidad con la participación de sus hijos menores en dichas actividades». Para Climent Gallart (2020), el pin parental supone «la potestad de los padres de vetar la asistencia de sus hijos a cualesquiera actividades escolares que puedan afectar a la sexualidad o a la moral, y que resulten intrusivas para la conciencia y la intimidad de los menores».

El establecimiento de esta medida encontró la oposición tajante del Ministerio de Educación del Gobierno de España, que cuestionó su constitucionalidad y requirió oficialmente su retirada. Ante la falta de respuesta al requerimiento, se interpuso un recurso contencioso-administrativo ante el Tribunal Superior de Justicia de Murcia (TSJM), que suspendió cautelarmente el pin parental por cuanto una sentencia estimatoria «podría quedar carente de virtualidad»,

6 Dichas mociones se han presentado -y rechazado- en parlamentos autonómicos como los de la Comunidad Valenciana, Principado de Asturias, Cantabria o la Comunidad de Madrid, entre otros. 
causando el perjuicio de la posible «no realización por los alumnos de una actividad obligatoria por no autorizarlo sus padres y madres, con la consiguiente no evaluación de la misma» ${ }^{7}$. Sin embargo, el TSJM no se pronunció sobre el fondo del recurso, que fue archivado ante la finalización del curso por la crisis del coronavirus, con la imposibilidad de aplicación de la normativa ${ }^{8}$.

El pin parental divide a la doctrina científica del Derecho (Álvarez Rodríguez, 2020). De un lado, Teruel Lozano (2021) rechaza los argumentos del Gobierno estatal y señala que éste es un asunto "abierto al juego democrático», sin que exista una vulneración del derecho a la educación, si bien puntualiza que la regulación tiene una base jurídica frágil, que se debía circunscribir a menores sin madurez suficiente y que el silencio debía ser positivo. En el mismo sentido, Contreras Mazarío (2021: 108) entiende que, si bien el Tribunal Supremo ha dicho que no existe un derecho general de objeción de conciencia el pin parental se enmarca en un claro supuesto de objeción. Sin embargo, entiende que se ha generado un inadecuado problema de seguridad jurídica, por haberse implementado a través de una norma reglamentaria que contradice la legislación autonómica, lo que podría resolverse con la interpositio legislatoris, mediante una norma con rango de ley.

Por otro lado, Climent Gallart (2020: 120), siguiendo la jurisprudencia del Tribunal Europeo de Derechos Humanos (TEDH), indica que el pin parental podría contradecirla, por cuanto «el derecho parental a que los hijos reciban una educación de acuerdo con sus propias convicciones no impide que los Estados puedan impartir, a través de la enseñanza, información o conocimientos que, de modo directo o indirecto, puedan tener un reflejo religioso o filosófico». También han cuestionado su constitucionalidad Pérez-Royo (2020), Salazar Benítez (2020), Suárez Llanos (2020), Gómez Abeja (2021) o Valero Heredia (2020). Por su parte, Rey Martínez (2021: 23) ha señalado que el pin parental es un «magnífico ejemplo de la artificiosidad del problema planteado», por cuanto es una cuestión que no genera ningún conflicto en la práctica diaria de los centros.

La controversia del pin parental sigue estando de máxima actualidad, tanto en la Región de Murcia como en otras Comunidades con gobiernos sostenidos por VOX, que ha exigido su implantación para la aprobación de los presupuestos. Por lo que respecta a la primera, las instrucciones de inicio del curso 2021-2022 ${ }^{9}$ no contemplan como tal el pin parental, pero recientes acontecimientos políticos apuntarían a su implementación. Por lo tanto, todo parece indicar que este conflicto jurídico seguirá estando de actualidad y que el Tribunal Constitucional podría pronunciarse sobre ello en el futuro.

\section{El régimen jurídico de las actividades complementarias en el sistema educativo}

El pin parental ha estado dirigido a dispensar la asistencia de las personas menores a las actividades complementarias impartidas en centros docentes por personal externo, que podríamos enmarcar en la educación no formal (Cotino Hueso, 2012: 62). Pues bien, para Teruel Lozano (2021: 7), «solo una adecuada

7 Nota de prensa del TSJM, 12 de marzo de 2020. Disponible en: https://bit.ly/3rGk1wt.

8 El Tribunal Superior de Justicia de Murcia archiva el recurso contra el veto parental porque el curso ha terminado. El País, 15-07-2020. Disponible en: https://bit.ly/2OdpoWj.

9 Las resoluciones de la Consejería de Educación, de 23 de julio de 2021, recogen un aumento de las obligaciones de información a las familias sobre el contenido de las actividades complementarias, fórmula similar a la implementada en la Comunidad de Madrid. 
delimitación del régimen jurídico de estas actividades complementarias permite valorar con precisión» la viabilidad de implantar legalmente el pin parental, aunque matiza que dicho régimen dista de ser claro.

El Real Decreto 1694/1995, de 20 de octubre, en el ámbito de la educación concertada, indica que las actividades complementarias son «las establecidas por el centro con carácter gratuito dentro del horario de permanencia obligada de los alumnos en el mismo y como complemento de la actividad escolar »10. Así, la Ley Orgánica 2/2006, de 3 de mayo, de Educación (LOE), señala en su artículo 121 que los centros podrán organizar actividades complementarias en uso de su autonomía pedagógica, organizativa y de gestión y que deberán incluirse en su programación general anual (art. 125 LOE), garantizando la participación de la comunidad educativa en la programación de la enseñanza (art. 27.5 CE).

En cuanto al marco competencial, el artículo 149.1.30. de la Constitución fija que el Estado tiene la competencia exclusiva en la regulación de las «normas básicas para el desarrollo del artículo 27», por lo que la competencia de las Comunidades Autónomas vendrá definida negativamente una vez fijado el alcance de este precepto (Cotino Hueso, 2012: 303)11. Así, todas las materias reguladas por Ley Orgánica tienen carácter básico, pero no todas las normas básicas han de ser aprobadas por Ley Orgánica (Díaz Revorio, 2002: 165), por lo que debemos analizar el carácter orgánico o no de los preceptos que regulan materia educativa por el Estado para desentrañar el margen de regulación de las Comunidades Autónomas. En este sentido, el artículo 6.4.b) de la Ley Orgánica 8/1985, de 3 de julio, reguladora del Derecho a la Educación (LODE), establece como un deber básico del alumnado «[p]articipar en las actividades formativas $y$, especialmente, en las escolares y en las complementarias gratuitas ${ }^{12}$.

Este precepto fue incorporado al ordenamiento a través de la Ley Orgánica 2/2006, de 3 de mayo, en virtud del apartado tercero de la Disposición Final Primera, que tiene rango de Ley Orgánica, según establece la Disposición Final Séptima de la $\mathrm{LOE}^{13}$. De esta forma, el precepto que establece el deber de participar en las actividades complementarias tiene carácter orgánico. Por lo tanto, si se debe excluir de la regulación autonómica la materia que tenga carácter orgánico (Cotino Hueso, 2012: 307), las Comunidades Autónomas no podrán suprimir a través de su legislación ordinaria el deber básico del alumnado de participar en las actividades complementarias gratuitas, pues esta obligación viene definida en un artículo con rango de ley orgánica ${ }^{14}$.

Así, entendemos que existe un deber jurídico del alumnado de participar en las actividades complementarias gratuitas, no así en las que supongan un desembolso dinerario, que son voluntarias para que no exista discriminación

10 La norma que regula los currículos de la Región de Murcia expresa que estas actividades son las «planificadas por los departamentos que utilicen espacios o recursos diferentes al resto de actividades ordinarias de la materia, aunque precisen tiempo adicional del horario no lectivo para su realización».

11 Para un desarrollo más profundo de la cuestión, véase Díaz Revorio (2002: 159 y ss.).

12 I artículo 6.1 de la LODE señala además que «[t]odos los alumnos y alumnas tienen los mismos derechos y deberes, sin más distinciones que las derivadas de su edad y del nivel que estén cursando".

13 La LO 3/2020, de 29 de diciembre, ratifica el carácter orgánico de la disposición que reforma la LODE.

14 Hay que tener en cuenta la flexibilización realizada por el Tribunal Constitucional (STC 137/1986, de 6 de noviembre) sobre las «materias conexas», en las que se permitiría a las Comunidades Autónomas con competencias asumidas entrar a regular, pero entendemos que no podrían contravenir el contenido de una materia con rango de Ley Orgánica regulada por el Estado (Díaz Revorio, 2002: 163-165). 
por motivos económicos (Gómez Abeja, 2021: 9). En sentido contrario, Teruel Lozano (2021: 7) entiende que, de una interpretación sistemática se desprende que todas las actividades complementarias son voluntarias, exista o no coste económico. En cualquier caso, a mi juicio, parece una interpretación jurídica forzada y que contravendría el sentido mismo de un precepto con carácter orgánico que establece expresamente como deber del alumnado el de participar en las actividades "complementarias gratuitas». Si se ha excluido expresamente de este deber aquellas que supongan un desembolso económico y se han mantenido las gratuitas, subsiste la obligación jurídica de participar en ellas.

Así, podemos llegar a una primera conclusión en virtud de la cual las resoluciones que implementaron el pin parental en la Región de Murcia contravenían la legislación orgánica estatal, al establecer una dispensa familiar para la asistencia a las actividades complementarias por parte del alumnado, una obligación jurídica que no puede ser exceptuada, mucho menos con una norma reglamentaria ${ }^{15}$. Pero es que, además, las normas que implementaron el pin parental no solo eran contrarias a la legislación estatal, sino que vulneraron la normativa autonómica (Teruel Lozano, 2021: 8). En efecto, a diferencia de lo que sucede en otras Comunidades (Gómez Abeja, 2021: 10), la norma que establece los currículos de la Región de Murcia ${ }^{16}$, dispone expresamente que las actividades complementarias son «evaluables a efectos académicos y obligatorias» ${ }^{17}$.

En suma, a nuestro juicio, cualquier norma autonómica que establezca el pin parental estará atentando directamente contra la distribución de competencias entre el Estado y las Comunidades Autónomas, por cuanto éstas no pueden regular el estatuto jurídico de derechos y deberes básicos de la comunidad educativa, ni mucho menos contravenir el contenido de un precepto de carácter orgánico a través de una ley ordinaria autonómica ${ }^{18}$. La asistencia a las actividades complementarias gratuitas es un deber básico del alumnado, por lo que el establecimiento de una dispensa familiar por parte de una Comunidad Autónoma -ya sea a través de una norma legal o reglamentaria-constituye una vulneración de la legislación orgánica que establece dicho deber jurídico e incorpora una objeción de conciencia encubierta que podría ser contraria a la Constitución.

15 Da igual el recurso jurídico que se use para implantar el pin parental, incluso una norma con rango de ley, pues vulneraría la Ley Orgánica, en una competencia exclusiva del Estado (Gómez Abeja, 2021: 11).

16 Decretos no. 198/2014, de 5 de septiembre (art. 25.3f), 220/2015, de 2 de septiembre (art. 33.3.e) y 221/2015, de 2 de septiembre (art. 26.3.e). Debemos señalar que se abrió una consulta pública para la modificación de los Decretos para establecer el pin parental (Gómez Abeja, 2021: 3).

17 Además, señala que «tendrán carácter voluntario para los alumnos aquellas que [...] precisen aportaciones económicas de las familias», lo que ratifica la obligatoriedad de las actividades gratuitas.

18 En ese caso se produciría una quiebra del principio de igualdad (art 6.1 LODE) en función de la Comunidad Autónoma en la que residan, sin perjuicio de la vulneración material del art. 27 CE. 


\section{El derecho fundamental a la educación y sus fines constitucionales}

Antes de profundizar en el análisis sobre la constitucionalidad del pin parental, nos detendremos en algunos aspectos generales del derecho a la educación, proclamado en el artículo 27 de la Constitución Española. Se trata de un precepto especialmente amplio, sin duda el más largo de los que regulan derechos fundamentales (Cotino Hueso, 2012: 8), que es fruto del consenso logrado en el proceso constituyente, no exento de conflicto, pues fue uno de los más polémicos de la Constitución (Alzaga Villaamil, 2016: 199) ${ }^{19}$. En este artículo se consiguió que confluyeran dos posiciones distintas sobre este derecho fundamental (Contreras Mazarío, 2020: 83), motivo por el que se proclama el derecho a la educación, junto con el reconocimiento de la libertad de enseñanza ${ }^{20}$. Pues bien, más allá de la discusión doctrinal sobre si este precepto incorpora varios derechos subjetivos autónomos ${ }^{21}$ o si se trata de un único derecho fundamental de contenido complejo (Aláez Corral, 2011: 94-98) ${ }^{22}$, su redacción reproduce la de los instrumentos internacionales de derechos humanos ${ }^{23}$. En este sentido, resulta muy relevante el recurso de concreción interpretativa que se concede al derecho internacional de los derechos humanos, en virtud del artículo 10.2 de la Constitución (Saiz Arnáiz, 1999), por lo que la jurisprudencia de órganos como el Tribunal Europeo de Derechos Humanos y el Comité Europeo de Derechos Sociales o las observaciones del Comité de los Derechos del Niño resulta de vital importancia.

En particular, el artículo 27.2 de la Constitución establece que la educación «tendrá por objeto el pleno desarrollo de la personalidad humana en el respeto a los principios democráticos de convivencia y a los derechos y libertades fundamentales». Este apartado sigue especialmente la senda de instrumentos internacionales de derechos humanos, lo que es una práctica habitual en el Derecho Comparado (Aláez Corral, 2011: 98-105) ${ }^{24}$. Existe división doctrinal sobre si se trata de una cláusula de «democracia militante» (Fernández-Miranda Campoamor, 2007: 150), pues se entiende que la Constitución toma partido e incurre en una cierta pérdida de neutralidad en su redacción (Aláez Corral,

19 Para un análisis más profundo del citado consenso constituyente, véase Nogueira (1988: 67-76).

20 Así, no nos debe resultar extraño que este derecho fundamental sea objeto de conflictos jurídico-políticos como el del pin parental, que, a juicio de Contreras Mazarío (2020: 81-82), es un ejemplo perfecto de cómo colisionan las dos visiones sobre educación y enseñanza presentes a lo largo de la historia.

21 Como defienden Cotino Hueso (2012: 8); Contreras Mazarío (2020: 83-84); o Díaz Revorio (2002: 23).

22 El Tribunal Constitucional (STC 86/1985, de 10 de julio, FJ $3^{\circ}$ ), alineado con el Tribunal Europeo de Derechos Humanos (STEDH, de 7 de diciembre de 1976, FJ 50), entiende las facultades incorporadas en el artículo 27 como una unidad, que se conectan mutuamente entre sí, en una relación de interdependencia.

23 Véanse el art. 26 Declaración Universal de los Derechos Humanos; arts. 13 y 14 del Pacto Internacional por los Derechos Económicos, Sociales y Culturales; arts. 28 y 29 de la Convención sobre Derechos del Niño; art. 2 del Protocolo Adicional no. 1 del Convenio Europeo de los Derechos Humanos; o incluso el art. 30 de la Carta de Derechos Fundamentales de la Unión Europea, entre otras normativas.

24 Como ejemplos, véanse el art. 24.3 de la Constitución de Bélgica, art. 73.2 de la Constitución de Portugal, art. 16.2 de la Constitución de Grecia, o el art. 14.5.a) de la Constitución de Austria. La doctrina destaca que «los derechos humanos deben ser [...] el punto de mira siempre presente cualquiera que sea la fase del desarrollo del proyecto educativo" para instaurar la cultura de los derechos (Sánchez Ferriz, 2000: 45). 
2011: 109). Siguiendo a Rey Martínez (2021: 2), la Constitución «no es ideológicamente neutral en el campo de la educación» ${ }^{25}$. Así, el llamado ideario educativo constitucional alcanza tanto a la escuela pública como a la privada (Cotino Hueso, 2012: 84) ${ }^{26}$.

Por otro lado, Aláez Corral (2011: 94) considera que el ideario es «un límite al ejercicio de las libertades educativas, además de un objetivo positivamente vinculante en la prestación del derecho a la educación ${ }^{27}$. Cámara Villar (1988: 2169) también señala que todo el artículo 27 es instrumental respecto al segundo apartado, en tanto que «configurador de los objetivos últimos del sistema $y$, por consiguiente, precepto que enmarca por una parte la posición de todos los centros educativos, limitándolos negativamente y activándolos con una directriz constitucional y, por otra, la de los propios escolares, dado que es el desarrollo libre y pleno de su personalidad (arts. 10. 1 y 27. 2), lo que explica la existencia de la misma institución educativa». Así, las facultades comprendidas en este derecho, como la libertad de enseñanza religiosa o moral de las familias ${ }^{28}$, están limitadas negativamente por los fines de la educación, lo que ha sido objeto de conflictos de derechos y es muy importante para el abordaje del pin parental. En este sentido, el ejercicio de las facultades que componen el derecho a la educación está delimitado por el «ideario educativo constitucional» (Aláez Corral, 2009a: 13) ${ }^{29}$.

Dicho esto, si bien el artículo 27.2 de la Constitución no reconoce derechos subjetivos, ni ampara pretensiones concretas (Cotino Hueso, 2012: 87) ${ }^{30}$, en tanto que es un principio que inspira positivamente al ordenamiento, el Tribunal Constitucional ha recurrido al ideario educativo para la resolución de conflictos relacionados con este derecho fundamental, como pasó con el fenómeno de la educación en casa (homeschooling) ${ }^{31}$ o la objeción de conciencia a la asignatura de Educación para la Ciudadanía ${ }^{32}$. Y, por ello, será precisamente a través del ideario educativo constitucional desde la perspectiva que analizaremos la problemática del pin parental en los próximos apartados.

\section{El reconocimiento del derecho a la educación sexual y de género en el plano internacional y la legislación estatal}

La organización política que propone el pin parental señala la educación sexual y de género como uno de los aspectos que más preocupa a las familias, pues sus contenidos podrían colisionar con las enseñanzas religiosas o morales que dan a sus hijas e hijos (art. 27.3 CE). Y, si bien la implementación del pin parental en la

25 Para una visión más desconfiada sobre el alcance de este precepto, véase Vidal Prado (2017: 53 y ss.).

26 Tomás y Valiente indicó en su voto particular a la STC 5/1981 que «contiene la definición del objetivo que debe perseguir la educación, cualquiera que sea la naturaleza, pública o privada, de cada centro docente, precepto que constituye lo que podría denominarse sin metáfora el "ideario educativo de la Constitución"».

27 Tal como lo ha entendido el Tribunal Constitucional (STC 5/1981, de 13 de febrero).

28 rt. 27.3 CE: «Los poderes públicos garantizan el derecho que asiste a los padres para que sus hijos reciban la formación religiosa y moral que esté de acuerdo con sus propias convicciones».

29 Lo que ha sido corroborado por el Tribunal Supremo (STS, de 14 de abril de 1998, FJ 4º).

30 Como ha dicho reiteradamente el Tribunal Constitucional (por todas, SSTC 5/1981, de 13 de febrero, FJ 70 y 337/1994, de 23 de diciembre, FJ 110).

31 STC 133/2010, de 2 de diciembre. Sobre este tema, véase Valero Heredia (2012).

32 SSTS, de 11 de febrero de 2009, que resuelve los recursos número 905/2008, 948/2008, $949 / 2008$ y 1013/2008. Para un análisis más amplio sobre esta cuestión véase Serrano Pérez (2009). 
Región de Murcia no estableció distinción sobre las temáticas de las actividades complementarias, hemos circunscrito este trabajo únicamente a la educación sexual y de género, por cuanto compartimos con Rey Martínez (2021: 22) que «el único tema realmente inflamable desde el punto de vista ideológico ha sido el relativo a los derechos de la comunidad LGTBi, esto es, la "normalidad" de la homosexualidad y/o la transexualidad, la educación afectivo-sexual, la plena legitimidad democrática del matrimonio homosexual y, en consecuencia, la existencia de distintos modelos constitucionales de familia» ${ }^{33}$.

La educación sexual no solo centra las preocupaciones -negativas- de algunas familias, también ha preocupado -positivamente- a los poderes públicos, por lo que la han incorporado en las normativas bajo la cobertura de los instrumentos internacionales. El artículo 27.2 de la Constitución marca como uno de los fines de la educación la enseñanza en «los derechos y libertades fundamentales», cuyas normas deben ser interpretadas de conformidad con los instrumentos internacionales sobre derechos humanos, en tanto que somos un «Estado internacionalmente integrado» (Torres del Moral, 2004: 1109). Así, la consagración de un derecho a la educación sexual en los instrumentos internacionales es muy importante, porque, como guía interpretativa de los derechos fundamentales (art. 10.2 CE), podríamos argumentar su encaje en el ideario educativo constitucional, hasta el punto de poder repeler o limitar objeciones de las familias -como el pin parental-sobre la base del derecho reconocido en el artículo 27.3.

Dicho esto, lo cierto es que la educación sexual está reconocida a nivel internacional como uno de los múltiples fines sociales que tiene la educación, en tanto que útil herramienta para el libre desarrollo de la personalidad (Cotino Hueso, 2012: 68-76) ${ }^{34}$. Así, cabe indicar que la educación sexual se ha enmarcado en el derecho a la protección de la salud (Nuevo López, 2011: 10) y también a la educación para la planificación familiar y la lucha contra el SIDA (Cotino Hueso, 2012: 73). Así, encontramos la educación sexual presente en el ámbito de la planificación familiar en el artículo 24.2.f) de la Convención sobre derechos del niño ${ }^{35}$ o en el artículo 10.h) de la Convención sobre la eliminación de todas las formas de discriminación contra la mujer, incluyéndola en su definición por el Comité para la eliminación de la discriminación contra la mujer.

Por otro lado, el artículo 11.2 de la Carta Social Europea recoge el compromiso de «establecer servicios educacionales y de consulta dirigidos a la mejora de la salud y a estimar el sentido de responsabilidad individual en lo concerniente a la misma» como una garantía del derecho a la salud. Este precepto ha servido para que el Comité Europeo de Derechos Sociales (CEDS) ${ }^{36}$ deduzca una obligación de los Estados signatarios en el aseguramiento del acceso universal a

33 Gómez Abeja (2021: 20) entiende que «[I]o que incomoda al partido ultraconservador, en realidad, son asuntos muy concretos, como la ideología de género, la educación sexual, o la diversidad sexual».

34 Para una visión más profunda sobre este asunto véase Muñoz (2010). Informe preliminar del Relator Especial de las Naciones Unidas sobre el derecho humano a la educación sexual integral. Montevideo: CLADEM.

35 El Comité de los Derechos del Niño de las Naciones Unidas ha recomendado en numerosas ocasiones a los Estados la inclusión de la educación sexual en las escuelas. Véase, por ejemplo, la Observación General no. 3 sobre VIH/SIDA y Derechos del Niño (2003: 13) y las Observaciones Finales sobre Colombia (2000: 48); Etiopía (2001: 61); Antigua y Barbuda (2004: 54); o Trinidad y Tobago (2006: 54), entre otras.

36 Órgano creado en virtud del artículo 25 de la Carta Social Europea de 1960, ratificada por España en 1980, y que realiza una interpretación autorizada de los derechos recogidos (Nuevo López, 2011: 125). 
la educación sexual y a la salud reproductiva. De la jurisprudencia elaborada por el CEDS destacamos el asunto INTERIGHTS contra Croacia ${ }^{37}$, en el que una ONG denunciaba lo contrario a lo que sucede con el pin parental: que en las escuelas croatas no se impartía una educación sexual y de salud reproductiva completa y adecuada para la infancia y adolescencia, por lo que, a través de esta decisión, como señala Jimena Quesada (2011: 206), se perfila el derecho a la educación sexual ${ }^{38}$. Pero es que, además, el CEDS indica que el derecho a la educación sexual debe asegurarse a la infancia escolarizada sin distinción, por lo que no debe existir discriminación en el acceso a este derecho por las personas menores, lo que se produce especialmente cuando dichas clases son opcionales o extraescolares (Jimena Quesada, 2011: 207) ${ }^{39}$.

Podríamos pensar en este punto que el CEDS excluye de la educación sexual algunos aspectos polémicos, relativos a la igualdad de género o la diversidad sexual, pero la enseñanza de estos valores también encuentra cobertura internacional. Al contrario, lo que sí ha indicado es que la educación sexual «no debe ser utilizada como un medio para reforzar los estereotipos envilecedores y que perpetúan formas de ultraje que contribuyen a la exclusión social de los grupos tradicionalmente marginados $u$ otros grupos confrontados a una antigua y constante discriminación, $u$ a otros tipos de prejuicios sociales que tienen como efecto negarles su dignidad humana» ${ }^{40}$. Así, el CEDS constató en materiales de Croacia manifestaciones contrarias al principio de discriminación por orientación sexual, al relacionar el VIH/SIDA con las personas homosexuales, incurriendo en estigmatizaciones discriminatorias (Jimena Quesada, 2011: 207).

El derecho a la educación sexual y para la igualdad de género se reconoce como un derecho de las personas menores en los instrumentos internacionales, pero también está plenamente incorporada en la normativa estatal. La Ley Orgánica 2/2010, de 3 de marzo, de salud sexual y reproductiva y de la interrupción voluntaria del embarazo ${ }^{41}$, establece la garantía de incorporar «la información y la educación afectivo sexual y reproductiva en los contenidos formales del sistema educativo», así como "la educación sanitaria integral y con perspectiva de género sobre salud sexual y salud reproductiva». Ello se concreta en el artículo 9, que señala que «el sistema educativo contemplará la formación en salud sexual y reproductiva, como parte del desarrollo integral

37 Reclamación n 45/2007, resuelta mediante decisión de fondo de 30 de marzo de 2009.

38 «La educación sexual y genésica debe formar parte de los programas escolares ordinarios. Las clases impartidas deben ser suficientes desde el punto de vista cuantitativo, esto es, en cuanto al número de horas y demás recursos empleados (docentes, formación de formadores, material pedagógico, etc.). La forma y el fondo de esta enseñanza, incluidos los programas y métodos didácticos, deben ser pertinentes, culturalmente apropiados y de calidad suficiente; en particular, debe garantizarse que las informaciones comunicadas sean objetivas, se basen en pruebas científicas recientes y no sean censuradas, sesgadas o deliberadamente falsas, por ejemplo en lo que concierne a la anticoncepción y los diferentes medios para preservar la salud sexual y genésica. Debe ponerse en marcha un procedimiento de control y evaluación de la enseñanza impartida con el fin de cumplir con los criterios mencionados».

39 Esto tiene una importancia capital al trasladarlo a la problemática del pin parental, pues con su implantación se pretende convertir en voluntarias las actividades complementarias de educación sexual, estableciendo una dispensa familiar a este deber jurídico. Esto último supondría, siguiendo al CEDS, una forma de discriminación de la infancia en el acceso al derecho a la educación sexual y de género.

40 CEDS, Decisión de fondo asunto INTERRIGHTS contra Croacia, de 30 de marzo de 2009.

41 Su exposición de motivos indica: "La Ley parte de la convicción, avalada por el mejor conocimiento científico, de que una educación afectivo sexual y reproductiva adecuada, [...] y la disponibilidad de programas y servicios de salud sexual y reproductiva es el modo más efectivo de prevenir, especialmente en personas jóvenes, las infecciones de transmisión sexual, los embarazos no deseados y los abortos». 
de la personalidad y de la formación en valores» ${ }^{42}$ y también en el artículo 10, que indica que se apoyará a los centros docentes «en la realización de actividades formativas relacionadas con la educación afectivo sexual, la prevención de infecciones de transmisión sexual y embarazos no deseados, facilitando información adecuada a los padres y las madres» ${ }^{43}$.

El Dictamen del Consejo de Estado sobre el Anteproyecto de esta Ley Orgánica expresa algo muy importante: «A la altura del tiempo actual no cabe duda que la educación sexual es un elemento imprescindible de una instrucción adecuada por exigencia de la propia protección del niño y adolescente de la que no puede privarle un derecho de veto absoluto por parte de sus padres, como estos no podrían privarle del derecho genérico a la educación» ${ }^{44}$. Esta afirmación del Alto Cuerpo Consultivo del Estado es trasladable a la problemática del pin parental, por cuanto se deduce que las familias no pueden privar absolutamente a la infancia y adolescencia de una educación sexual que, en la actualidad, no solo está perfectamente conectada con el contenido del derecho a la educación, sino que es un elemento fundamental para la protección de la infancia y adolescencia ${ }^{45}$. Y es que, precisamente a través del pin parental, las familias podrían no autorizar la participación de las personas menores en ninguna de las actividades complementarias de educación sexual que se imparten en los centros docentes, privándoles absolutamente de esa formación en la escuela.

Por otro lado, la Ley Orgánica 3/2020, de 29 de diciembre, por la que se modifica la Ley Orgánica 2/2006, de 3 de mayo, de Educación (LOMLOE) proclama a la educación sexual como principio inspirador del sistema educativo español ${ }^{46}$. Además, incluye la educación afectivo-sexual, la igualdad de género y la aceptación de la diversidad sexual como un objetivo básico en todas las etapas de la enseñanza, desde la educación primaria, a la ESO y el bachillerato ${ }^{47}$, mientras que antes estaba considerada como un objetivo únicamente de la educación secundaria obligatoria (Cotino Hueso, 2012: 73). A mayor abundamiento, la disposición adicional vigésima quinta, establece en su apartado tercero que los centros docentes «deberán necesariamente incluir y justificar en su proyecto educativo las medidas que desarrollan para favorecer y formar en igualdad en todas las etapas educativas, incluyendo la educación para la eliminación de la violencia de género, el respeto por las identidades, culturas, sexualidades y su diversidad, y la participación activa para hacer realidad la igualdad». De esta forma, la educación sexual y de género ha adquirido una importancia capital en la LOMLOE, porque se convierte no solo en una facultad enmarcada en la

42 Con un enfoque integral que contempla la igualdad, el reconocimiento y aceptación de la diversidad sexual, la prevención de enfermedades de transmisión sexual o de embarazos no deseados, entre otros.

43 Para un análisis más profundo sobre esta normativa véanse Nuevo López (2011) y Llano Torres (2010).

44 Dictamen del Consejo de Estado n. 1384/2009, de 17 de septiembre, p. 36. Es necesario comentar con Nuevo López (2011: 139-140) que el dictamen alude a la necesidad de no caer en el adoctrinamiento.

45 El artículo 30 de la Ley Orgánica 8/2021, de 4 de junio, de protección integral a la infancia y la adolescencia frente a la violencia, contempla la educación afectivo sexual como uno de los principios educativos básicos, que debe recibirse transversalmente en todas las etapas, adaptada al nivel madurativo.

46 El artículo 1.I) cita como principios del sistema educativo «[e]l desarrollo de la igualdad de derechos, deberes y oportunidades, el respeto a la diversidad afectivo-sexual y familiar, el fomento de la igualdad efectiva de mujeres y hombres a través de la consideración del régimen de la coeducación de niños y niñas, la educación afectivo-sexual, adaptada al nivel madurativo, y la prevención de la violencia de género [...]».

47 Arts. 17.d), 19.2, 23.k), 24.5, 25.6 y 33.b), entre otros preceptos. 
autonomía pedagógica y organizativa, sino en una obligación jurídica de todos los centros docentes, como parte de la formación integral a la que se refiere el Tribunal Constitucional (STC 133/2010, de 2 de diciembre, FJ 70).

De esta forma, el Estado, siguiendo los instrumentos internacionales, ha optado por incluir la educación sexual en las escuelas a través de contenidos que se deben incorporar a la programación general de la enseñanza, no como una asignatura específica ${ }^{48}$, sino de forma transversal a través de actividades complementarias recogidas en la programación general de cada centro educativo y que son obligatorias para el alumnado. En este sentido, ya hemos dicho que el Comité Europeo de Derechos Sociales ha entendido que el derecho a la educación sexual y de género debe asegurarse a la infancia escolarizada sin distinción alguna, por lo que las personas menores no pueden ser víctimas de discriminación en el acceso a este derecho, lo cual se produce cuando dichas clases son opcionales o extraescolares, como se pretende con el pin parental.

\section{La educación sexual y de género como parte del ideario educativo consti- tucional: límites y garantías para las familias}

Los instrumentos internacionales y la normativa estatal reconocen el derecho a la educación sexual, como un bloque de contenidos que integra la igualdad de género y la diversidad sexual, que debe formar parte de la programación general de la enseñanza y, por tanto, de los proyectos de los centros. El Tribunal Supremo ha dicho que las familias no tienen un derecho ilimitado a oponerse a la programación general de la enseñanza ${ }^{49}$, por lo que no se permiten dispensas o exenciones sobre la base del artículo 27.3, como se pretende con el pin parental. En definitiva, el hecho de que la educación sexual y de género encuentre cobertura en los instrumentos internacionales y la normativa estatal, nos hace concluir que forma parte del ideario educativo constitucional, en el marco de la formación integral que debe recibir la infancia y adolescencia para el libre desarrollo de su personalidad, por lo que no es admisible el pin parental (Rey Martínez, 2020: 22).

Para el Tribunal Constitucional la educación no se contrae a una mera transmisión de conocimientos de la enseñanza reglada, sino que aspira a posibilitar el libre desarrollo de la personalidad, en el respeto a los principios democráticos de convivencia y a los derechos y libertades fundamentales, que posibilite su plena integración en la sociedad (STC 133/2010, de 2 de diciembre, FJ 70). Y ello solo puede ser posible a través de una «educación integral» ${ }^{50}$, lo que implica, siguiendo al TEDH, la necesidad de una educación no adoctrinadora, plural, neutral, objetiva, democrática, respetuosa con las plurales posiciones ideológicas, religiosas o morales y que facilite la integración social de las personas menores, pues la educación es el principal instrumento de socialización y una herramienta imprescindible para la convivencia democrática (Valero Heredia,

48 En Dinamarca, el TEDH avaló la obligatoriedad de la asignatura como una medida legítima, necesaria y proporcional (STEDH, de 7 de diciembre de 1976, Kjeldsen, Busk Madsen y Pedersen contra Dinamarca).

49 STS de 11 de febrero de 2009, que resuelve el recurso nº. 905/2008, FJ $8^{\circ}$.

50 En palabras de Rey Martínez (2021: 26) una «educación inclusiva y de calidad», bajo una interpretación evolutiva de lo que significa una «educación para la libertad, equitativa y democrática» que entienda la sociedad como una realidad dinámica, integre todas las formas de diversidad en la escuela como parte del ideario educativo, para salvaguardar así la igualdad y la garantía de los derechos y libertades fundamentales. 
2018: 272). Una educación basada, pues, en los llamados «valores republicanos», que conciba nuestra sociedad pluralista de un modo abierto e inclusivo, para garantizar la integración de todas las formas de diversidad (Velasco Arroyo, 2004: 203).

Así, Aláez Corral $(2011,126)$ señala que se deben generar contextos educativos que faciliten la integración social, ofreciendo una visión lo menos sesgada posible del mundo, por lo que «la sustracción del educando menor de edad a la socialización e integración necesarias para el aprendizaje de los principios y valores necesarios para su convivencia democrática respetando los derechos de los demás y desarrollando libremente su personalidad, sea no escolarizándole, sea objetando en su nombre [...] implican una lesión de su derecho a la educación (art. 27.1 CE) y no está amparada por el derecho de los padres a elegir la formación religiosa y moral del art. 27.3 CE» ${ }^{51}$.

Para fundamentar el pin parental, algunos sectores critican que la educación sexual viene presidida por la «ideología de género», lo que se contestaría con un fragmento de una Sentencia del Tribunal Supremo que señala que «además de no explicar con claridad qué entienden por ella, no nos dicen en qué contenido de la norma se plasman los efectos negativos que la adjudican ${ }^{52}$. Ya hemos dicho que la Constitución no es ideológicamente neutral en la educación, que toma partido por la enseñanza en el pleno desarrollo de la personalidad humana, en el respeto a los principios democráticos de convivencia y a los derechos y libertades fundamentales, por lo que no entendemos los efectos negativos que se predican de educar sobre la base de la igualdad de género, consagrada en el artículo 14 de la Constitución.

En este punto, podría argumentarse también que los efectos limitativos del artículo 27.2 de la Constitución no alcanzan a las actividades complementarias, donde se imparte la educación sexual. Sin embargo, debemos recordar que una parte de la doctrina y el Tribunal Constitucional (STC 5/1981, de 13 de febrero, FJ $7^{\circ}$ ), han afirmado que el ideario educativo se impone incluso a las enseñanzas no regladas: tanto si se abordan en centros que sí la imparten, como en los que no, por cuanto la inspiración positiva y el alcance negativo del ideario educativo constitucional está vinculado con el proceso sistemático y continuado de la enseñanza (Cotino Hueso, 2012: 85), por lo que alcanzaría también a las actividades complementarias de educación sexual.

Así, el pin parental, al permitir una dispensa familiar a las actividades complementarias de educación sexual, choca directamente con el marco constitucional y contradice la jurisprudencia del Tribunal Supremo que ya ha indicado que del artículo 27.3 no puede deducirse un derecho ilimitado de las familias a oponerse a la programación general de la enseñanza, ni tampoco a establecer objeciones, ni exenciones a ésta. Pero es que, además, el pin parental vulnera los instrumentos internacionales y la normativa estatal que reconoce el derecho a la educación sexual, por lo que resulta de dudosa constitucionalidad, sin perjuicio de las garantías que debe revestir su impartición para la protección de los derechos de las familias. Y es que, aun reconociendo la cobertura normativa y los relevantes efectos positivos de la educación sexual integrada en el ideario educativo constitucional, existen derechos de las familias que podrían verse afectados a los que se debe prestar atención, a la luz de lo establecido en el

51 Incluso expresa que «dogmas filosóficos o religiosos que pretendan superponerse a los valores comunes cívico-democráticos, expresión de la moral pública recogida en el art. 27.2 CE como ideario educativo constitucional [...] no pueden entenderse amparados por el derecho a elegir del art. 27.3 CE» (ibídem).

52 STS de 11 de febrero de 2009, que resuelve el recurso nº. 948/2008, FJ $11^{\circ}$. 
citado artículo 27.3 de la Constitución. Para adentrarnos en las garantías que debe revestir la educación sexual y de género, recurriremos a la jurisprudencia del Tribunal Europeo de Derechos Humanos que se ha pronunciado en numerosas ocasiones ante recursos de familias que entendían que la impartición de contenidos sexuales en las escuelas chocaba con su derecho a educar a sus hijas e hijos, de acuerdo con sus propias convicciones religiosas o morales ${ }^{53}$.

En el asunto Kjeldsen, Busk Madsen y Petersen contra Dinamarca, algunas familias se negaron a que sus hijas e hijos asistieran a las clases de educación sexual que se impartían en las escuelas danesas, por lo que solicitaron una exención. El asunto llegó al Tribunal de Estrasburgo, que desestimó sus pretensiones al entender que el derecho de las familias a procurar a sus hijos e hijas una educación conforme a sus convicciones, no puede impedir que los poderes públicos impartan contenidos de tipo religioso o moral, de forma directa o indirecta (Climent Gallart, 2020: 112). En este sentido, el TEDH indicó que es difícil que la educación sexual no implique «ciertas apreciaciones que puedan invadir el campo religioso o filosófico, pues se trata de una materia en que los juicios de realidad desembocan fácilmente en juicios de valor». Lo decisivo es que los contenidos no supongan «un intento de adoctrinamiento tendente a preconizar un comportamiento sexual determinado, [...], a exaltar el sexo ni a incitar a los alumnos a dedicarse precozmente a prácticas peligrosas para su equilibrio, su salud o su futuro, o reprensibles para muchos padres». De esta forma, el TEDH entiende que se debe prestar atención a la manera en que se imparten estos contenidos, de modo que se garantice que «las convicciones religiosas y filosóficas de los padres no sean contrariadas [...] por imprudencia, falta de discernimiento o proselitismo intempestivo» ${ }^{54}$.

Por lo tanto, una de las primeras garantías que debe revestir la educación sexual es que la información se transmita de manera objetiva, crítica y pluralista ${ }^{55}$. A la vista de los hechos, el TEDH entendió que el establecimiento de la obligatoriedad de una asignatura de educación sexual en las escuelas públicas era una medida legítima, necesaria y proporcional. Y no solo eso, sino que la existencia de esa asignatura era plenamente compatible con la facultad de las familias de enseñar a sus hijas e hijos de acuerdo con sus convicciones religiosas o morales, eso sí, fuera del ámbito de la escuela, lo cual sería a nuestro juicio trasladable a la problemática del pin parental. Por supuesto, también existe una garantía adicional para las familias en la salvaguarda de sus intereses, que también recuerda el TEDH en esta y otras sentencias: el derecho a elegir para la educación de sus hijas e hijos un centro de enseñanza privado que tenga un ideario acorde a sus convicciones religiosas o morales ${ }^{56}$. De esta forma, si las familias entienden que la educación sexual que se imparte en las escuelas públicas atenta contra sus convicciones siempre puede elegir otras opciones pedagógicas para la educación de sus hijas e hijos.

53 Sobre este asunto véase Climent Gallart (2020) o Monterroza Baleta (2021).

54 La Sentencia tiene un voto particular del Juez Verdross que ha sintetizado Nuevo López (2011: 134-135).

55 Ello concuerda con la jurisprudencia del Tribunal Supremo que establece una diferencia en el ideario educativo constitucional, entre la enseñanza en valores comunes, en los que no cabe adoctrinamiento y otros que no son compartidos, que deben impartirse desde la más exquisita objetividad y el más prudente distanciamiento (STS, de 11 de febrero de 2009, que resuelve el recurso $n^{\circ} .905 / 2008$, FJ 60).

56 En Dinamarca cabe el homeschooling, aquí es inconstitucional desde STC 133/2010, de 2 de diciembre. 
EI TEDH recurrió a la doctrina jurisprudencial descrita anteriormente para inadmitir una demanda interpuesta en el asunto Jiménez Alonso y Jiménez Merino contra España ${ }^{57}$, en el que padre e hija recurrieron ante el suspenso obtenido por esta última en la asignatura de Ciencias Naturales, debido a que no asistió a clase por los contenidos sobre sexualidad humana que se impartían en una escuela de Cantabria. En este caso, el TEDH insiste en que los contenidos del material curricular utilizado para la materia comentada fueron diseñados para informar de manera objetiva y científica sobre una cuestión de interés general y que no suponía adoctrinamiento para mantener un comportamiento sexual determinado, por lo que no afectaría al derecho de las familias a guiar y aconsejar a sus hijas e hijos de conformidad con sus creencias ${ }^{58}$. EI TEDH recuerda de nuevo que la familia tiene la opción de matricular a su hija en un colegio privado que tenga un ideario educativo más acorde a sus creencias (Nuevo López, 2011: 141).

Dicho esto, para concluir con este apartado, existen preocupaciones legítimas de las familias sobre los contenidos de educación sexual que se imparten en las escuelas, pues como afirma Nuevo López (2011: 138) la introducción en el sistema educativo de la educación sexual y en salud reproductiva incide indudablemente en el derecho de los padres, una «incidencia que los padres están obligados a soportar». Pero esas preocupaciones no pueden convertirse en un veto absoluto para que el Estado cumpla con sus responsabilidades educativas acordes con el marco constitucional e internacional, ni mucho menos puede dar lugar a una carta blanca para que el alumnado asista a las actividades que las familias autoricen, que legitime una suerte de geometría variable en los contenidos a impartir en las escuelas en función de si concuerdan con la ideología familiar, como se pretende con el pin parental (Vázquez Alonso, 2020).

Esto no quiere decir que la impartición de educación sexual esté desprovista de garantías. Para cumplir con el principio de neutralidad y salvaguardar los derechos de las familias, las asignaturas o actividades complementarias de educación sexual y de género deben impartirse de la manera más exacta, precisa, objetiva y científica posible. Ello implica, siguiendo la jurisprudencia del TEDH, que dichas actividades no podrán suponer un intento de adoctrinamiento para preconizar un comportamiento sexual determinado, exaltar el sexo, ni incitar al alumnado a prácticas sexuales peligrosas. Sin embargo, de ello no podemos deducir que cualquier elemento que contravenga las concepciones que las familias libremente inculcan a la infancia suponga de por sí una quiebra del mencionado principio de neutralidad. Dicho de otro modo, si una familia educa a sus hijas e hijos en la heterosexualidad como norma y la repulsa de la diversidad sexual, el hecho de que se imparta una actividad complementaria donde se enseñe que las personas pueden ser heterosexuales, lesbianas, gais, trans o bisexuales, bajo el cumplimiento del principio de igualdad, no supondría una quiebra del principio de neutralidad que protege a las familias, precisamente por su encaje jurídico en el ideario educativo de la Constitución.

El hecho de que, a nuestro juicio, no sea admisible el pin parental no implica que se nieguen los derechos de las familias, que siguen existiendo, aunque

57 Decisión de inadmisión TEDH, de 25 de mayo de 2000, Jiménez Alonso y Jiménez Merino contra España.

58 EI TSJ de Cantabria desestimó la demanda argumentando que el derecho de las familias a educar de acuerdo con sus convicciones no era ilimitado, debía ser observado en relación con los derechos del resto, por lo que no era ajustado a derecho «tratar de imponer una diferencia de trato o discriminación positiva a partir de las propias ideas, ni elegir o predeterminar en función de un ideario particular el contenido del proyecto educativo de un centro público» (STSJ Cantabria, de 23 de marzo de 1998, FJ 12º). 
sometidos a los límites constitucionales. Así, las familias tienen derecho a escoger un centro docente de titularidad privada o concertada cuyo ideario concuerde con sus convicciones religiosas o morales (art. 27.6 CE). También tienen derecho a participar en la programación de la enseñanza, como parte de la comunidad educativa (art. $27.5 \mathrm{CE})^{59}$. Por último, las familias cuentan con la posibilidad de acudir a los tribunales ante concretos abusos que se detecten en la impartición de estas actividades complementarias de educación sexual, en el ejercicio de su derecho a la tutela judicial efectiva (Rey Martínez, 2021: 23).

\section{Conflictos relativos a la titularidad y ejercicio de los derechos educativos}

\section{Las personas menores como titulares del derecho fundamental}

El artículo 27.1 de la Constitución se refiere a «todos» al enunciar el derecho a la educación, pero nos detendremos en su titularidad relacionada con el pin parental. Díaz Revorio (2002: 23) señala que en el derecho a la educación participa una pluralidad de sujetos a quienes el ordenamiento reconoce determinadas facultades, un elemento de complejidad para su tratamiento jurídico (Cotino Hueso, 2012: 259). Dicho esto, el titular habitual del derecho a la educación es el alumnado menor de edad, «eje gravitatorio de todo el régimen constitucional de la enseñanza y del sistema educativo, que no tiene otro fin principal que lograr el pleno desarrollo de su personalidad» (Cotino Hueso, 2012: 260), además de ser el principal beneficiario de las facultades del precepto constitucional (Aláez Corral, 2011: 92), sin perjuicio de otros accesorios, por lo que las familias no participan en la enseñanza en su propio interesés, sino en el de sus hijos e hijas (Cotino Hueso, 2012: 66). Sin embargo, el artículo 27.3 establece un derecho subjetivo de titularidad familiar, aunque su ejercicio no debe menoscabar los derechos de las personas menores y está limitado por el ideario constitucional y el interés superior del menor.

Ello se explica por la limitación de la capacidad de las personas menores, que hace que el ejercicio de algunos derechos se encargue temporalmente a quienes tienen un mandato de protección (art. $39 \mathrm{CE}$ ) para que los ejerciten en su nombre e interés (Aláez Corral, 2003: 57) ${ }^{60}$. Ahora bien, esto puede ser problemático, pues algunos aspectos del derecho a la educación están vinculados con la libertad de enseñanza religiosa o moral. Sobre ello, Aláez Corral (2009a: 11) señala que el artículo 27.3 establece un derecho-función en interés ajeno, pues las personas menores son las titulares ${ }^{61}$. Por contra, Cotino Hueso (1999: 132) señala que es un derecho subjetivo de las familias que ampara su interés de que «reciban la formación religiosa y moral acorde a sus propias creencias» ${ }^{62}$. Por su parte, Valero Heredia (2019: 203) considera que tienen un

59 Las familias están representadas en el Consejo Escolar donde se aprueba la programación general que debe contener las actividades complementarias (art. 127.b) LOE).

$60 \mathrm{El}$ autor indica que «si los textos constitucionales e internacionales atribuyen a los padres dicha facultad, sólo puede ser para ponerla al servicio de los intereses del educando menor de edad, es decir, para evitar que la satisfacción por parte del Estado del derecho a la educación se proyecte sobre los alumnos de manera que se les adoctrine filosófica y moralmente. Lo cual es congruente con que en nuestro ordenamiento [...] los padres no sean constitucionalmente titulares de un derecho "natural" a educar a sus hijos, sino únicamente de un deber de cuidado y protección [...]».

61 Coincide con Suárez Llanos (2020: 127).

62 Este derecho subjetivo se va desvaneciendo con el tiempo en favor de las personas menores, en cuanto alcanzan la capacidad natural para ejercer su libertad ideológica o religiosa (Cotino Hueso, 1999: 133). 
carácter temporal ${ }^{63}$, siendo decisiva la voluntad de las personas menores con "un grado de madurez suficiente»; e instrumental, porque deben orientarse al ideario constitucional ${ }^{64}$.

En este sentido, el Tribunal Constitucional ha dicho que las personas menores «son titulares plenos de sus derechos fundamentales, en este caso, de sus derechos a la libertad de creencias y a su integridad moral, sin que el ejercicio de los mismos y la facultad de disponer sobre ellos se abandonen por entero a lo que al respecto puedan decidir aquellos que tengan atribuida su guarda y custodia o [...] patria potestad, cuya incidencia sobre el disfrute del menor de sus derechos fundamentales se modulará en función de la madurez del niño y los distintos estadios en que la legislación gradúa su capacidad de obrar» (STC 141/2000, de 29 de mayo, FJ 50) ${ }^{65}$. En efecto, el derecho de las familias de brindar una formación moral y religiosa según sus convicciones puede chocar con el derecho de la infancia a tener creencias diferenciadas, como titulares de su propia libertad de pensamiento, conciencia y religión. De acuerdo con la jurisprudencia constitucional, si se diera este conflicto de derechos, deberá resolverse en favor del interés superior del menor.

Por otro lado, en nuestro ordenamiento jurídico existen situaciones en las que las personas menores pueden tomar sus decisiones libremente y ejercitar autónomamente sus derechos, según su evolución y madurez (Aláez Corral, 2013) ${ }^{66}$. Incluso, el Tribunal Constitucional (STC 99/2019, de 18 de julio) reconoció que las personas menores trans con «suficiente madurez» y «situación estable de transexualidad» podían solicitar la rectificación registral del sexo (Salazar Benítez, 2019). Por ello, no se entiende cómo el pin parental se aplica indistintamente para todas las personas menores, desde infantil a bachillerato, sin modulación alguna por la edad y madurez del alumnado. Efectivamente, en la regulación de la Región de Murcia, las familias eran las únicas con capacidad para decidir si el estudiantado menor asistía o no a las actividades complementarias, sin que existiera facultad de decisión autónoma, según su edad o madurez ${ }^{67}$.

En ello han reparado incluso quienes entienden que el pin parental es acorde a la Constitución, que matizan que, en su caso, debería ser la persona menor de edad quien decida, siempre que tenga madurez suficiente. Así, Teruel Lozano (2021: 10) señala que es una exigencia constitucional que el pin parental se circunscriba «a aquellos supuestos en los que el menor no tenga madurez suficiente para tomar sus propias decisiones. [...] Si el menor tiene madurez suficiente, sus padres no pueden oponerse a que asista a una actividad educativa que a él le interese», por lo que propone excluir de su aplicación al alumnado a partir

63 Art. 5 de la Convención sobre derechos del niño: «en consonancia con la evolución de sus facultades».

64 En todo caso se debe primar el «derecho del menor a recibir una formación integral que contribuya al libre desarrollo de la personalidad» (Valero Heredia, 2018: 261).

65 Además, el TC señala que «frente a la libertad de creencias de sus progenitores y su derecho a hacer proselitismo de las mismas con sus hijos, se alza como límite [...] aquella misma libertad de creencias que asiste a los menores de edad, manifestada en su derecho a no compartir las convicciones de sus padres o a no sufrir sus actos de proselitismo, o más sencillamente, a mantener creencias diversas a las de sus padres, máxime cuando las de éstos pudieran afectar negativamente a su desarrollo personal. Libertades y derechos de unos y otros que, de surgir el conflicto, deberán ser ponderados teniendo siempre presente el "interés superior" de los menores de edad (arts. 15 y $16.1 \mathrm{CE}$ en relación con el art. $39 \mathrm{CE}$ )».

66 Como la edad de consentimiento sexual, el consentimiento en el ámbito sanitario, la toma de decisiones sobre medidas de protección de menores, entre otras.

67 Algo similar a la que ha sucedido con la asignatura de religión, que es voluntaria, pero cuya elección se abandona a las familias, a diferencia de lo que sucede en otros países (Troncoso Reigada, 1996: 254). 
de $3^{\circ}$ de la ESO. En el mismo sentido, Contreras Mazarío (2021: 108) considera que el pin parental «debe quedar circunscrito [...] al ámbito en los que los menores no tengan madurez suficiente para tomar sus propias decisiones (esto es, Enseñanza Primaria y, todo lo más, $1^{\circ}$ y $2^{\circ}$ de la ESO), ya que si el menor tiene dicha madurez será a éste a quien corresponda, en todo caso, la toma de dicha decisión». En este sentido, el pin parental no debería poder aplicarse de igual manera a todas las personas menores, independientemente de su edad o madurez, por lo que, en el hipotético -e improbable ${ }^{68}$ - caso de que fuera admisible constitucionalmente, las familias tendrían capacidad de decidir solo si sus hijas e hijos no tuvieran madurez suficiente para hacerlo.

\section{La posición singular de las familias para decidir la formación religiosa y moral de la infancia}

El artículo 27.3 de la Constitución reconoce «el derecho que asiste a los padres para que sus hijos reciban la formación religiosa y moral que esté de acuerdo con sus propias convicciones" ${ }^{69}$. Se trata de un derecho subjetivo cuya titularidad recae en los padres y las madres, conectado con la libertad de enseñanza y también con el derecho a elegir centros docentes privados o concertados con un ideario determinado (Díaz Revorio, 2002: 99)70, además de ser una manifestación del derecho a la libertad ideológica y religiosa (art. 16.1 CE) integrada expresamente en el derecho a la educación (Cotino Hueso, 2012: 156). Así, según Díaz Revorio (2002: 103) existen dos dimensiones: una negativa, que implica que las actividades deben acomodarse a la libertad de conciencia del alumnado y sus familias; y otra positiva, con la garantía de que se impartan enseñanzas acordes con las opciones religiosas o morales, de carácter voluntario para el estudiantado.

Ante el ejercicio de este derecho para manifestar la disconformidad hacia determinados contenidos impartidos en la escuela, el Tribunal Constitucional y el TEDH han desestimado habitualmente las citadas pretensiones, precisamente por entender que esta facultad de las familias se encuentra limitada negativamente por los fines de la educación, que deben primar en la programación de la enseñanza. De manera específica sobre la libertad ideológica y religiosa, el Tribunal Supremo ha entendido que no tiene que ser incompatible con una enseñanza de las diversas concepciones del pluralismo de la sociedad, siempre que se haga con neutralidad y sin adoctrinamiento. Ello implica informar sobre la realidad y sus diversas concepciones, «sin presiones dirigidas a la captación de voluntades a favor de alguna de ellas», por lo que debe ser «desarrollada con un sentido crítico" y, al abordar planteamientos ideológicos, religiosos o morales individuales, que generen diferencias sociales, «la enseñanza se debe limitar a exponerlos e informar sobre ellos con neutralidad, sin ningún adoctrinamiento, para, de esta forma, respetar el espacio de libertad consustancial a la convivencia constitucionalı>11.

68 Porque aun así los derechos de las familias quedarían limitados por el ideario educativo constitucional en el que encaja la educación sexual y de género.

69 Este precepto constitucional también encuentra cobertura en otros instrumentos internacionales en materia de derechos humanos (Climent Gallart, 2020: 105-108).

70 También en la escuela pública, aunque ello no implica que toda la enseñanza esté orientada a principios religiosos o morales, pues la neutralidad ideológica preside la enseñanza (Díaz Revorio, 2002: 103).

71 STS, de 11 de febrero de 2009, que resuelve el recurso n. 905/2008, FJ $6^{\circ}$. 
Con respecto a la objeción de conciencia ${ }^{72}$, el Tribunal Supremo afirma que la Constitución «no proclama un derecho a la objeción de conciencia con alcance general», pues ello equivaldría a «hacer depender la eficacia de las normas jurídicas de su conformidad con cada conciencia individual, lo que supondría socavar los fundamentos mismos del Estado democrático de derecho ${ }^{73}$. Y también cierra la puerta a un derecho específico de objeción de conciencia, fundamentado en el artículo 27.3 de la Constitución, pues los apartados segundo y tercero del precepto constitucional se limitan mutuamente entre sí, es decir, «el Estado no puede llevar sus competencias educativas tan lejos que invada el derecho de los padres a decidir sobre la educación religiosa y moral de los hijos; pero, paralelamente, tampoco los padres pueden llevar este último derecho tan lejos que desvirtúe el deber del Estado de garantizar una educación "en el respeto a los principios democráticos de convivencia y a los derechos y libertades fundamentales" ${ }^{\prime 74}$. Dicho esto, en la problemática del pin parental, como aclara Contreras Mazarío (2021: 101) ni siquiera han sido las familias las que han planteado esa pretendida objeción de conciencia a las actividades complementarias, como sí sucedió con la asignatura de Educación para la Ciudadanía. En este caso, ha sido un gobierno autonómico el que ha establecido -sin ser competente- una dispensa de las familias por razones de conciencia al cumplimiento de un deber jurídico de asistencia a las actividades complementarias.

Por lo tanto, a nuestro juicio, cuando nos referimos al pin parental no nos encontramos sin más ante una cuestión de pretendida objeción de conciencia de las familias sobre la base del artículo 27.3 de la Constitución frente a unos contenidos obligatorios por razones de conciencia, pues ese no es, ni ha sido un problema generalizado en nuestro país, salvo supuestos concretos ${ }^{75}$. Se trata de una objeción de conciencia encubierta establecida por una Comunidad Autónoma, que ha hecho viable un derecho inexistente en nuestro ordenamiento jurídico y que se opone al ideario educativo de la Constitución. A pesar de la inconstitucionalidad del pin parental, las familias siguen teniendo una posición singular en el ámbito educativo y son titulares de un derecho subjetivo para educar a sus hijos e hijas de acuerdo con sus convicciones, sin que de ello pueda derivarse un derecho a privarles de su derecho a recibir educación sexual y de género en la escuela.

\section{Conclusiones}

La normativa autonómica que estableció el pin parental en la Región de Murcia en el curso 2019-2020, era contraria al ordenamiento jurídico, pues vulneraba lo dispuesto en la legislación orgánica estatal que establece el deber básico del alumnado de participar en las actividades complementarias gratuitas y también se oponía a la propia normativa autonómica que establecía dicha obligatoriedad. Por este motivo, se ha pretendido modificar la norma que establece los

72 Sobre este asunto de la objeción de conciencia, véase Gómez Abeja (2015).

73 STS de 11 de febrero de 2009, que resuelve el recurso n. 905/2008, FJ $8^{\circ}$. Si bien cabría reconocer dispensas por razones de conciencia en una norma con rango de ley, como Teruel Lozano (2021: 7) y Contreras Mazarío (2021: 106) entienden que debía haberse establecido el pin parental, aunque esta posibilidad podría corresponder al legislador orgánico (Gómez Abeja, 2021: 11).

74 Ibídem.

75 Lo que da cuenta de la artificiosidad del problema planteado (Rey Martínez, 2021: 23). 
currículos educativos para implantar de esta forma el pin parental. Sin embargo, a nuestro juicio, por cuestiones de carácter competencial, ninguna norma jurídica autonómica, aunque tenga rango de ley, podría establecer una dispensa familiar para la asistencia a las actividades complementarias gratuitas, por cuanto este deber jurídico viene establecido en un precepto con rango de Ley Orgánica, por lo que las Comunidades Autónomas no pueden oponerse de ninguna forma a su contenido, ni siquiera mediante una ley ordinaria.

El pin parental pretende que las familias decidan si sus hijas e hijos pueden participar en las actividades complementarias de educación sexual y de género, por cuanto podrían afectar al derecho del artículo 27.3 de la Constitución. Sin embargo, tal como ha dicho el Tribunal Constitucional, la educación va más allá de la mera transmisión de conocimientos, pues tiene como objeto el ideario educativo constitucional, que modula y limita negativamente el resto de las facultades. Pues bien, a nuestro juicio, la educación sexual y de género forma parte del ideario educativo constitucional, al estar consagrada en los instrumentos internacionales, así como en el ordenamiento jurídico español como un principio inspirador del sistema educativo y un objetivo a cumplir transversalmente en todas las etapas educativas, por lo que la organización de las actividades complementarias de educación sexual no solo es una posibilidad de los centros, sino un deber jurídico.

Ahora bien, que la educación sexual se encuentre enmarcada en el ideario educativo constitucional, no significa que no se respeten los derechos de las familias. De esta forma, el Tribunal Europeo de Derechos Humanos ha venido entendiendo que la obligatoriedad de la educación sexual en las escuelas públicas era una medida legítima, necesaria y proporcional, pero los contenidos deben impartirse de manera objetiva, crítica y pluralista, sin adoctrinamiento. En cualquier caso, si las familias no están conformes con los contenidos de educación sexual, cuentan con garantías para la salvaguarda de sus derechos, como la participación en la programación de la enseñanza, la elección de un centro privado o concertado con un ideario acorde a sus convicciones o incluso recabar la tutela de los tribunales ante concretas vulneraciones, pero no tienen un derecho ilimitado a oponerse a la programación de la enseñanza, ni tampoco existe en nuestro ordenamiento jurídico un derecho a la objeción de conciencia.

La titularidad del derecho fundamental a la educación recae en las personas menores, como principales beneficiarias del sistema educativo en cuyo centro radican, sin perjuicio de que, dada su limitada capacidad de obrar, las familias sean titulares de un derecho subjetivo de darles una formación moral o religiosa alineada con sus convicciones. Pero debemos aclarar que se trata de un derecho temporal e instrumental, que con el paso del tiempo se va desvaneciendo en favor del alumnado menor cuando va adquiriendo la madurez suficiente y que, en caso de conflicto, debe primar el interés superior del menor. Es por ello por lo que no se entiende cómo el pin parental se pretende establecer de forma indistinta para todas las personas menores, de tal manera que las familias podrían no autorizar que alguien incluso de diecisiete años acuda a una actividad complementaria de educación sexual, aunque tenga madurez suficiente como para decidirlo por sí misma. Al no establecerse ninguna individualización en función de la edad y madurez de las personas menores, son las familias en exclusiva las que tendrían que decidir qué contenidos puede recibir el alumnado en la escuela, sin que su opinión cuente en absoluto, lo que entendemos cuestionable desde un punto de vista jurídico.

En definitiva, a nuestro juicio, el pin parental es inconstitucional, desde un punto de vista formal y material. Si, tal como establece la Constitución, la educación de nuestro país tiene por objeto el libre desarrollo de la personalidad en 
el respeto de los derechos y libertades fundamentales, las familias no pueden evitar que se impartan contenidos que de por sí aborden la diversidad sexual, la igualdad de género o la salud sexual, aunque éstos confronten con los valores en los que educan a sus hijas e hijos. Es más, la infancia y adolescencia tiene derecho a recibir educación sexual y para la igualdad de género como parte del ideario educativo constitucional, precisamente para la protección de sus derechos en el ámbito educativo y ello no puede venir limitado por los derechos de las familias que, en todo caso, son temporales e instrumentales, pues lo que debe primar en todo caso el interés superior de las personas menores como titulares que son del derecho fundamental a la educación.

\section{Bibliografía}

Aláez Corral, B. (2003). Minoría de edad y derechos fundamentales. Madrid: Tecnos. Aláez Corral, B. (2009a). Ideario educativo constitucional y respeto a las convicciones morales de los padres: a propósito de las Sentencias del Tribunal Supremo sobre "Educación para la Ciudadanía". El Cronista del Estado social y democrático de derecho, 5, 24-33. Se sigue por su disposición en la página personal del autor, con numeración propia, pp. 22. Disponible en: https://bit.ly/3ycx5gt.

Aláez Corral, B. (2009b). El ideario educativo constitucional como fundamento de la exclusión de la educación diferenciada por razón de sexo de la financiación pública. Revista Española de Derecho Constitucional, 86, 31-64.

Aláez Corral, B. (2011). El ideario educativo constitucional como límite a las libertades educativas. Revista Europea de Derechos Fundamentales, 17, 91-129.

Aláez Corral, B. (2013). El ejercicio autónomo de los derechos fundamentales por el menor de edad. Revista Europea de Derechos Fundamentales, 21, 37-78.

Álvarez Rodríguez, I. (2020). Debatiendo la constitucionalidad del pin parental, E-Prints Complutense. Se sigue por su disposición como working-paper en la página web del repositorio de producción académica en abierto de la UCM, pp. 14. Disponible en: https://bit.ly/2MFUEfm.

Alzaga Villaamil, O. (2016). Comentario sistemático a la Constitución Española de 1978. Madrid: Marcial Pons.

Cámara Villar, G. (1988). Sobre el concepto y los fines de la educación en la Constitución española». En Introducción a los derechos fundamentales. Madrid: Ministerio de Justicia.

Climent Gallart, J. A. (2020). El pin parental y la jurisprudencia del TEDH. Actualidad Jurídica Iberoamericana, 13, 102-121.

Contreras Mazarío, J. M. (2021). Valores educativos, ideario constitucional y derecho de los padres: la cuestión del "pin o censura parental". Revista de Derecho Político, 110, 79-112. Disponible en: https://doi.org/10.5944/ rdp.110.2021.30329

Cotino Hueso, L. (1999). Reflexiones en favor de una concepción funcional de las libertades de la enseñanza. Una perspectiva diferente con la que abordar el diseño constitucional del sistema educativo. Revista Cuadernos de la Cátedra Fadrique Furió Ceriol, 22-23. Se sigue por su disposición en la página personal del autor, con numeración propia, pp. 48. Disponible en: https://bit.ly/3DOjwnK.

Cotino Hueso, L. (2012). El derecho a la educación como derecho fundamental. Especial atención a su dimensión social prestacional. Madrid: Centro de Estudios Políticos y Constitucionales. 
Díaz Revorio, F. J. (2002). Los Derechos Fundamentales del Ámbito Educativo en el Ordenamiento Estatal y Autonómico de Castilla-La Mancha. Ediciones Parlamentarias de Castilla-La Mancha.

Fernández-Miranda Campoamor, A. (2007). Educación para la ciudadanía. Una perspectiva constitucional. En Educación en valores. Ideología y religión en la escuela pública (147-153). Madrid: Centro de Estudios Políticos y Constitucionales.

Gómez Abeja, L. (2015). Las objeciones de conciencia. Madrid: Centro de Estudios Políticos y Constitucionales.

Gómez Abeja, L. (2021). Apuntes constitucionales sobre el pin parental. Actas del XVIII Congreso de la Asociación de Constitucionalistas de España: Educación y Libertades en la democracia constitucional. Se sigue por su disposición en la página web del Congreso, pp. 20. Disponible en: https://bit.ly/3sT7lUu. Jimena Quesada, L. (2000). La educación en derechos humanos y democracia en el marco del estado internacionalmente integrado: plano universal, terreno regional y ámbito comparado. En L. Cotino Hueso (coord.), Derechos, deberes y responsabilidades en la enseñanza (pp. 56-98). Valencia: Generalitat Valenciana.

Jimena Quesada, L. (2011). Educación sexual y no discriminación en la jurisprudencia del Comité Europeo de Derechos Sociales. Revista Europea de los Derechos Fundamentales, 17, 197-219.

Llano Torres, A. (2010). Papel del Estado y derechos de los padres en la educación sexual y reproductiva. Foro, Nueva época, 11-12, 319-351.

Marrades, A.; Sevilla, J.; Calero, M. L.; y Salazar Benítez, O. (2019). El lenguaje jurídico con perspectiva de género. Algunas reflexiones para la reforma constitucional. Revista de Derecho Político, 105, 127-160. Disponible en: https://doi.org/10.5944/rdp.105.2019.25270

Monterroza Baleta, V. (2021). El derecho de los padres a escoger el tipo de educación para sus hijos de acuerdo a sus convicciones religiosas y morales -caso pin parental-, interpretado a partir de la jurisprudencia del Tribunal Europeo de Derechos Humanos. Actas del XVIII Congreso de la Asociación de Constitucionalistas de España: Educación y Libertades en la democracia constitucional. Se sigue por su disposición en la página web del Congreso, pp. 14. Disponible en: https://bit.ly/3mhOXC5.

Muñoz, V. (2010). Educación sexual, derecho humano: la piedra y el viento. El derecho humano a la educación sexual integral. Montevideo: CLADEM.

Nogueira, R. (1988). Principios Constitucionales del Sistema Educativo Español. Madrid: Centro de Publicaciones del Ministerio de Educación y Ciencia.

Nuevo López, P. (2011). Educación sexual y derechos fundamentales: contribución a un debate necesario. Revista de Derecho Político, 80, 117-148.

Pérez-Royo, J. (2020). La respuesta constitucional al veto parental. eldiario.es, 20-01-2020. Disponible en: https://bit.ly/3rNZZ3d.

Rey Martínez, F. (2021). El ideario educativo constitucional: objeto de enseñanza y parámetro de validez del sistema educativo. Actas del XVIII Congreso de la Asociación de Constitucionalistas de España: Educación y Libertades en la democracia constitucional. Se sigue por su disposición en la página web del Congreso, pp. 33. Disponible en: https://bit.ly/31zWAua.

Saiz Arnáiz, A. (1999). La apertura constitucional al derecho internacional y europeo de los derechos humanos: el artículo 10.2 de la Constitución española. Madrid: Consejo General del Poder Judicial.

Salazar Benítez, O. (2019). El derecho a la identidad sexual de las personas menores de edad. Comentario a la STC 99/2019, de 18 de julio de 2019. Revista de Derecho Constitucional Europeo, 32. 
Salazar Benítez, O. (2020). El pin parental y el derecho a la educación. eldiario. es, 18-01-2020. Disponible en: https://bit.ly/3umwoPN.

Sánchez Ferriz, R. (2000). Inserción de las cuestiones planteadas en nuestro marco constitucional. En L. Cotino Hueso (coord.), Derechos, deberes y responsabilidades en la enseñanza (Análisis jurídico-práctico a la luz de las exigencias constitucionales). Valencia: Generalitat Valenciana.

Serrano Pérez, M. M. (2009). La objeción de conciencia a educación para la ciudadanía (comentario a las SSTS de 11 de febrero de 2009). Teoría y Realidad Constitucional, 23, 457-479.

Sevilla Merino, J. (2018). Derechos, Constitución y lenguaje. Corts: Anuario de derecho parlamentario, 31 (extra), 81-104.

Suárez Llanos, L. (2020). El derecho a la educación: sus brechas de justicia, conciencia y género. Revista Telemática de Filosofía del Derecho, 23, 99-129.

Teruel Lozano, G. M. (2021). Pin Parental e ideario educativo-constitucional: una cuestión abierta al debate democrático. Actas del XVIII Congreso de la Asociación de Constitucionalistas de España: Educación y Libertades en la democracia constitucional. Se sigue por su disposición en la página web del Congreso, pp. 12. Disponible en: https://bit.ly/3wkxUDS.

Torres Del Moral, A. (2004). El Estado internacionalmente integrado. En Estado de Derecho y democracia de partidos (109 y ss.). Madrid: Universidad Complutense de Madrid.

Torres Del Moral, A. (2015). Estado de Derecho y democracia de partidos. Una teoría del Estado constitucional contemporáneo. Madrid: Editorial Universitas.

Troncoso Reigada, A. (1996). La clase de religión y su alternativa constitucional. Revista Vasca de Administración Pública, 45 (1), 241-289.

Valero Heredia, A. (2012). Ideario educativo constitucional y «homeschooling»: a propósito de la Sentencia del Tribunal Constitucional 133/2010, de 2 de diciembre. Revista Española de Derecho Constitucional, 94, 411-442.

Valero Heredia, A. (2018). Integración social y derecho a la educación: a propósito de la Sentencia de 10 de enero de 2017, del Tribunal Europeo de Derechos Humanos. Revista de Estudios Políticos, 180, 255-274. Disponible en: https:// doi.org/10.18042/cepc/rep.180.09

Valero Heredia, A. (2019). Perfiles constitucionales del derecho a la educación y la libertad de enseñanza en el ordenamiento jurídico español. Revista Vasca de Administración Pública, 115, 191-213.

Valero Heredia, A. (2020). El pin parental es inconstitucional. infolibre.es, 20-012020. Disponible en: https://bit.ly/2R4cSJK.

Vázquez Alonso, V. (2020). La cara y la cruz: ¿Vulnera el "pin parental" el artículo 27 de la Constitución? Actualidad Jurídica Aranzadi, 960.

Velasco Arroyo, J. C. (2004). Republicanismo, constitucionalismo y diversidad cultural. Más allá de la tolerancia liberal. Revista de Estudios Políticos (Nueva Época), 125, 181-209.

Vidal Prado, C. (2017). El derecho a la educación en España. Bases constitucionales para el acuerdo y cuestiones controvertidas. Madrid: Marcial Pons 